\title{
Generalized lichen amyloidosis and hyperthyroidism: coincidence or association
}

\author{
Müzeyyen Gönül1', Seray Külcü Çakmak², Serra Kayaçatin² \\ 1Dışkapı Yıldırım Beyazıt Education and Research Hospital, Ankara, Turkey \\ Head: Prof. Dr. Nurettin Karaoğlanoğlu \\ ${ }^{2}$ Ankara Numune Education and Research Hospital, Ankara, Turkey \\ Head: Prof. Dr. Nurullah Zengin
}

Postep Derm Alergol 2013; XXX, 4: 265-267

DOI: $10.5114 /$ pdia.2013.37039

\begin{abstract}
A 76-year-old white man presented with severe pruritic eruption on both of the extremities and lumbar area for 2 years. The dermatological examination showed multiple, $1-2 \mathrm{~mm}$ sized, hyperpigmented and hyperkeratotic papules which coalesced to form poorly delineated plaques spread on the lumbosacral area, lateral and extensor surfaces of thighs, arms and forearms. The histopathological examination revealed eosinophilic amorphous material in papillary dermis that was stained positively with crystal violet stain. The patient was diagnosed as generalized lichen amyloidosis (LA) clinically and histopathologically. Routine laboratory tests were within normal limits except thyroid function tests. The thyroid stimulating hormone level was decreased, while the thyroxine level was increased. Ultrasonography showed enlarged and heterogeneous thyroid gland. Thyroid autoantibodies were within normal limits. An association between LA and other diseases such as atopic dermatitis, lichen planus, mycosis fungoides, chronic urticaria, HIV infection, multiple endocrine neoplasia type 2A, and angiolymphoid hyperplasia with eosinophilia have been defined. However, there is no reported LA case associated with hyperthyroidism in the literature. We think that the same etiologic factor might have triggered both diseases, or hyperthyroidism, by causing the itching, might have induced the occurrence or spread of LA.
\end{abstract}

Key words: lichen amyloidosis, hyperthyroidism.

\section{Case report}

A 76-year-old white man came to the dermatology outpatient clinic with severe pruritic eruption. He said that the eruption occurred on both of the thighs 2 years ago. His own and his family history did not reveal any health problem. The dermatological examination showed multiple, 1-2 mm sized, hyperpigmented and hyperkeratotic papules which coalesced to form poorly delineated plaques spread on the lumbosacral area, lateral and extensor surfaces of thighs, arms and forearms (Figure 1). The complete blood count, urine analysis, biochemical tests, erythrocyte sedimentation rate, complements, chest $\mathrm{X}$-ray and abdominal ultrasonography were normal. Antinuclear and anti-DNA, anti-HBV, anti-HCV, anti-HIV antibodies and HBs Ag were negative. The thyroid stimulating hormone (TSH) level was decreased $(0.01 \mu \mathrm{lU} / \mathrm{ml}$, normal: 0.27-4.2 $\mu \mathrm{lU} / \mathrm{ml})$, while the thyroxine (T4) level was increased $(1.88 \mathrm{ng} / \mathrm{ml}$, normal: 0.93-1.7 ng/ml). Ultrasonography showed enlarged and het- erogeneous thyroid gland. Thyroid autoantibodies were within normal limits. Thyroid scintigraphy was planned but he did not continue his etiologic investigation of thyroid disease because his son died at that time. Later, the patient did not come for follow up. Histopathological examination of the skin lesions revealed hyperkeratosis, acanthosis, eosinophilic amorphous material in papillary dermis. This material was stained positively with crystal violet stain (Figure 2). The patient was diagnosed as generalized lichen amyloidosis (LA) clinically and histopathologically. His lesions did not respond to topical steroids and oral anti-histamines. Phototherapy (UV-B) was planned for the lesions but he did not come for therapy.

\section{Discussion}

Amyloidosis is characterized by extracellular deposition of amyloid that is an abnormal fibrillar form of nor-

Address for correspondence: Müzeyyen Gönül MD, Dışkapı Yıldırım Beyazıt Education and Research Hospital, İskitler Ankara, 06100 Ankara, Turkey, phone: 05326667249, e-mail: muzeyyengonul@gmail.com Received: 16.04.2013, accepted: 23.06.2013. 


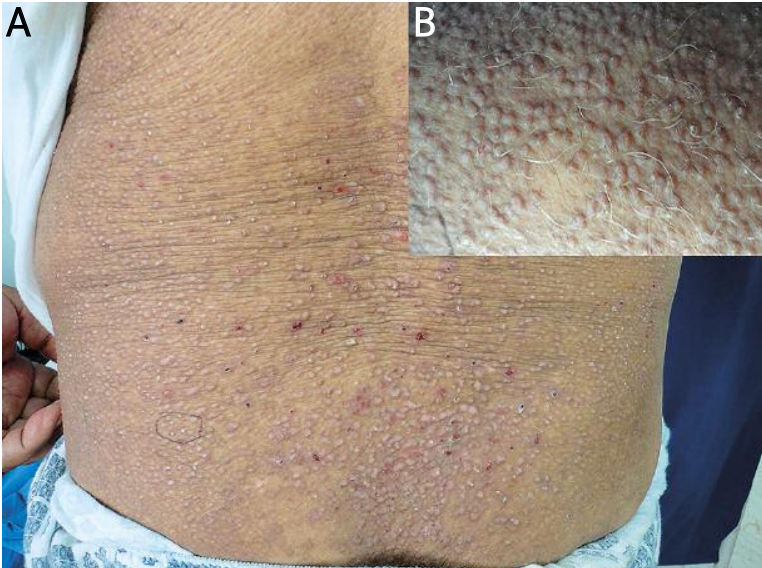

Fig. 1. A - Hyperpigmented and hyperkeratotic papules on the lumbosacral area. B - The closer appearance of the lesions

mal soluble autologous protein. Primary localized cutaneous amyloidosis is the deposition of amyloid in normal skin without visceral deposition [1, 2]. It is classified into three major types as macular, lichen and nodular amyloidosis [2, 3].

Clinically, LA is characterized by discrete, pruritic, hyperkeratotic papules that may coalesce into plaques. The most common site of involvement is the shins [1-9]. Lichen amyloidosis is a rare disease among white people [1, 2]. It appears very rarely in a generalized form [1]. Our case had generalized LA that involved both upper and lower extremities and lumbosacral area.

Genetic and viral factors have been identified as possible causes. It has been suggested that chronic scratching might be the provoking factor although not all of the patients have itching $[1,8]$. It is still unknown why the amyloid materials accumulate in the skin. Amyloid deposits are thought to be derived from degenerated keratin peptides of apoptotic keratinocytes transformed into amyloid fibrils. Chronic scratching and rubbing may induce keratinocyte degradation and amyloid formation $[1,4,5,10]$.

The therapeutic options include topical and intralesional steroids, calcipotriene, UV-B, oral retinoids and dermabrasion [1, 9]. UV-B therapy was planned for our case but he did not continue the treatment.

An association between LA and other diseases such as atopic dermatitis, lichen planus, mycosis fungoides, chronic urticaria, HIV infection, multiple endocrine neoplasia type $2 \mathrm{~A}$, and angiolymphoid hyperplasia with eosinophilia have been defined $[3,4,6,11]$. A case of LA associated with ankylosing spondylitis and autoimmune thyroiditis has been reported previously [2]. However, there is no reported LA case associated with hyperthyroidism in the literature. Our case had LA as well as hyperthyroidism. We do not know if this concomitant occurrence of LA and hyperthyroidism is a coincidence or if there is a role of this association in the etiopathogenesis of LA. As the patient had
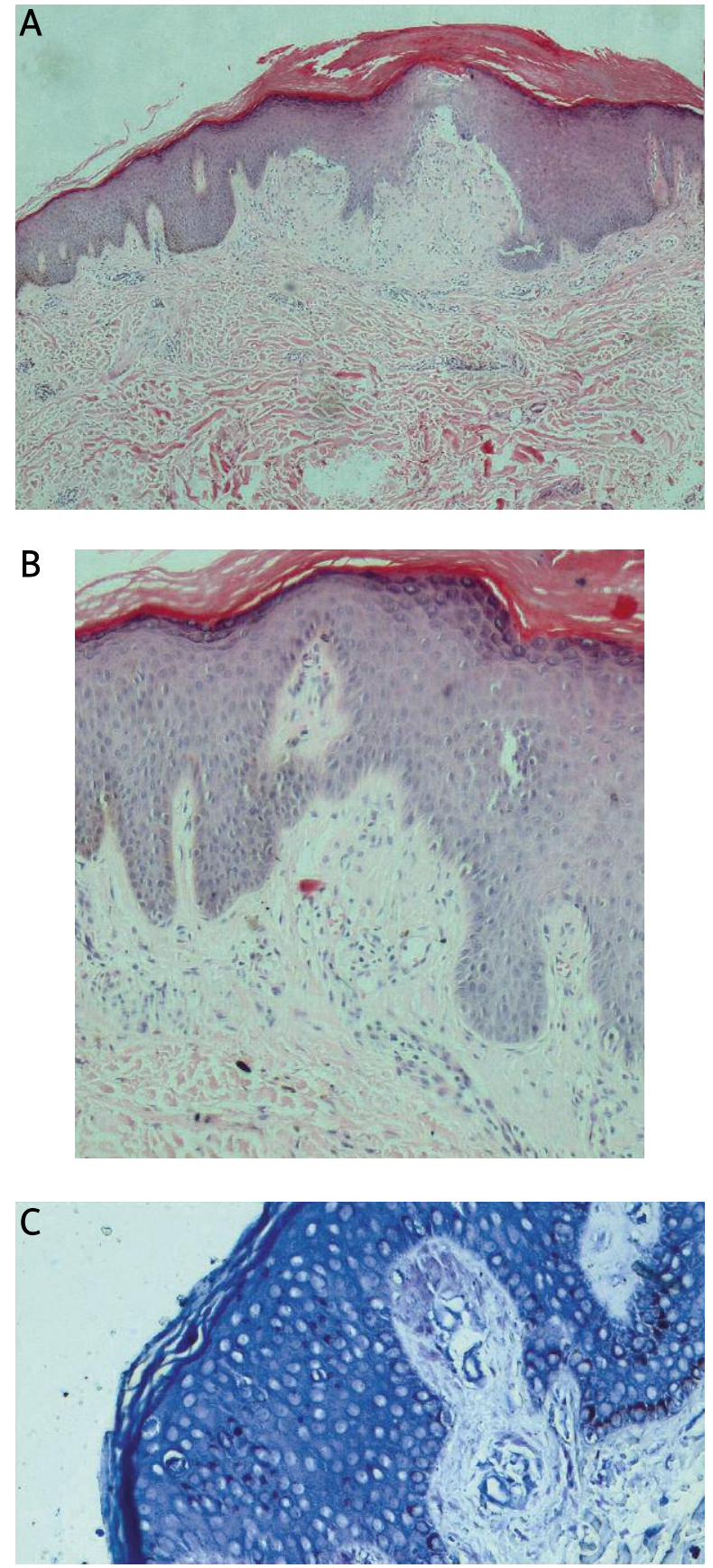

Fig. 2. A - Hyperkeratosis, acanthosis, eosinophilic amorphous material in papillary dermis $(H+E$ 40x). B - The closer appearance of the histopathologic figure $(H+E$ 100x). $\mathrm{C}$ - Amyloid deposits positively stained with crystal violet (Crystal violet 200×)

not been examined before elsewhere, the duration of the thyroid disease is unknown. So we cannot say that there is a temporal relationship between thyroid disease and LA, but we think that the same etiologic factor might have triggered both diseases, or hyperthyroidism, by causing the itching, might have induced the occurrence or spread of LA. 


\section{References}

1. Tursen U, Kaya TI, Dusmez D, Ikizoglu G. Case of generalized lichen amyloidosis. Int J Dermatol 2003; 42: 649-51.

2. Apaydin R, Bilen N, Bayramgürler D, et al. Lichen amyloidosis, ankylosing spondylitis and autoimmune thyroiditis: coincidence or association? J Eur Acad Dermatol Venereol 2000; 14: 135-7.

3. Salim T, Shenoi SD, Balachandran C, Mehta VR. Lichen amyloidosus: a study of clinical, histopathologic and immunofluorescence findings in 30 cases. Indian I Dermatol Venereol Leprol 2005; 71: 166-9.

4. Hongcharu W, Baldassano M, Gonzalez E. Generalized lichen amyloidosis associated with chronic lichen planus. J Am Acad Dermatol 2000; 43: 346-8.

5. Yalçin B, Artüz F, Gür Toy G, et al. Generalized lichen amyloidosus associated with chronic urticaria. Dermatology 2003; 207: 203-4.

6. Gül U, Kiliç A, Bilgili S, et al. Lichen amyloidosis with face involvement. Int J Dermatol 2008; 47: 1201-3.

7. Oiso N, Yudate T, Kawara S, Kawada A. Successful treatment of lichen amyloidosus associated with atopic dermatitis using a combination of narrowband ultraviolet B phototherapy, topical corticosteroids and an antihistamine. Clin Exp Dermatol 2009; 34: e833-6.

8. Ramírez-Santos A, Labandeira J, Monteagudo B, Toribio J. Lichen amyloidosus without itching indicates that it is not secondary to chronic scratching. Acta Derm Venereol 2006; 86: 561-2.

9. Choi JY, Sippe J, Lee S. Acitretin for lichen amyloidosus. Australas J Dermatol 2008; 49: 109-13.

10. Biliński P, Wojtyła A, Kapka-Skrzypczak L, et al. Epigenetic regulation in drug addiction. Ann Agric Environ Med 2012; 19: 491-6.

11. Dziechciaż M, Guty E, Wojtowicz A, Filip R. Social and health care needs of elderly people living in the countryside in Poland. Ann Agric Environ Med 2012; 19: 746-50. 